\title{
Forum
}

\section{Conflicts in Offshore Waters}

\author{
J. C. Hines
}

There has been some correspondence about conflicts in inshore waters in recent issues of the Journal. I would like to raise some questions about a problem which can arise in the open sea. I must admit to being a yachtsman, and so do not have the expertise of all the contributors to the previous discussion. In any occupation, the professional always has the advantage over the amateur, but many in both groups know this and amateurs in many activities, not only at sea, have been grateful for the opportunity to increase their expertise as a result of the help and advice that the professional can give. It has been said that ignorance is a voluntary misfortune. I believe that many yachtsmen are aware of this, feel ashamed of those who are not, and would hope that the professionals recognize that, as in any large enough group, there can be bad apples who do not represent the whole.

The problem I want to raise is when a yacht appears to be on a collision course with a commercial vessel in open waters in weather conditions bad enough to cause problems in a small vessel, although possibly only mildly uncomfortable in a commercial ship. Avoidance of merchant vessels in the open sea in these conditions in a typical cruising yacht, with husband and wife crew - only one person on watch and the other one asleep - is a common problem. Some of your previous contributors clearly have experience of operating under sail, but not all may be aware that there are manoeuvres which can be difficult under sail in some combinations of wind and sea. For example, a gybe in strong winds (especially shortly after a wind shift, such that the wind is across the sea) requires some care and may take some time. These are also the conditions in which yacht autopilots are least effective, especially in small yachts where the motion is greatest. Hand steering may be necessary, which means that taking bearings, let alone leaving the tiller to plot the position, is difficult. Consider this situation. With a tiller in one hand, we are struggling to keep the yaw down to $20^{\circ}$ each side of the course, and the compass is swinging through an even bigger arc. It would be hard to use the hand-bearing compass as a full-time occupation, even more difficult while steering, so the standard deviation of the reading would be very large.

In these circumstances, the sight of a commercial vessel on what may be a collision course raises a number of questions. Are we really on a collision course or does the ship's more sophisticated navigational equipment on a more stable platform enable the professional seaman to know that there is no hazard so that the best thing that we can do to avoid confusion is to hold on? Have we been seen? We all assume that the commercial ship has a radar set which is on, but most of us know that this is no guarantee of being seen. Recent correspondence in Yachting World has shown that it is easy to find commercial ships where the radar set is not on as a matter of course but, at the time of writing, I have not seen an explanation of why this should be so. Should we alter course anyway, even though this breaches our obligation, duty, to maintain course and speed and risks creating the very problem we want to avoid? If we change course, the change which is easier for us may also be the one which would worsen the commercial 
vessel's position if she has seen us and does intend to change course. Things can be more difficult at night, when it is harder to estimate distance off. Lights may have just appeared through murk, may be within five minutes of us and it will take that long to set up and execute a gybe safely, but the merchant ship may have seen us on radar for over a quarter of an hour. The old recommended strategy was to shine the torch or ignite a white flare.

Another strategy is to use vHF, although there are mixed opinions about the merits of this. I know that there is a dislike in some areas about the use of vHF for collision avoidance. However I have heard commercial ships calling on Ch. I6 and agreeing avoidance tactics. Indeed, there are some ports where it is recommended that all ships monitor the port control channel, and also some where it is mandatory to report, even if only passing through the entrance channels. I, like many other yachtsmen, keep the vHF set on with a cockpit loudspeaker (to avoid disturbing the sleep of the watch below) and sometimes a handset near the steering position for use in such circumstances. There have been times when I have called on Ch. I 6 , identified our position, relative bearings and course in the hope of agreeing a strategy with the commercial vessel. When a reply is obtained, the exchange is always courteous and helpful, one or both of us changes course and we rarely have to make the more difficult manoeuvre. However, it is common experience among yachtsmen that very few of these calls will be answered. Would any of your contributors like to help us by explaining this and suggesting the most appropriate strategies for the benefit of both groups?

If I may presume so far, might I suggest that a common factor in this subject, and that of conflicts in inshore waters, is that yachtsmen often do not know the constraints affecting commercial shipping or their intended changes of course. Communication to provide information would help. Much has been done to help yachtsmen to foresee the changes in inshore waters but some manoeuvres in the open sea can remain puzzling. Although not a rough weather situation, I remember being overtaken in perfect visibility by a coaster of about 500 g.t on an almost identical course and doing about 8 knots to our 6 . We must have been visible for over an hour. We were obliged to turn away to avoid being run down, but the vessel then turned right across our bows to a position which could have been reached by passing us on the other side. I presume that there was a reason. A short vHF call, however improper, would have enabled the master to forewarn us of his intentions and it would have been easy for us to move to a parallel course a few hundred yards to one side while he was still several miles astern.

KEY WORDS

I. Collision avoidance. 2. Small boat navigation. 3. Communications.

\section{Stability, Trim and Stress as Navigational Considerations}

\section{Captain T. Fales}

I INTRODUCTION. A vessel's stability affects her seaworthiness, certain stresses to which her hull and machinery are subjected and thus her speed of advance and the comfort and safety of those aboard. Her draught requires certain minimum depths of water, limits her speed in certain wind and sea conditions, affects the way she handles in all circumstances and her fuel consumption. Trim affects her seaworthiness, handling, fuel consumption and required depth of water. The bending moments and shear stresses 